\title{
Mortality Factors for Cirrhotics in an Ivorian University Hospital (Ivory Coast)
}

\author{
Jean Baptiste Okon*, Mamadou Diakite, Fabrice Ake, Olivier Koffi Kouadio, Amadou Kone \\ Hepato-Gastroenterology Department, University Hospital Center of Bouake, Bouake, Ivory Coast \\ Email: ${ }^{\star}$ okonanassi@yahoo.fr
}

How to cite this paper: Okon, J.B., Diakite, M., Ake, F., Kouadio, O.K. and Kone A. (2020) Mortality Factors for Cirrhotics in an Ivorian University Hospital (Ivory Coast) Open Journal of Gastroenterology, 10, 231-241.

https://doi.org/10.4236/ojgas.2020.109022

Received: July 17, 2020

Accepted: September 4, 2020

Published: September 7, 2020

Copyright $\odot 2020$ by author(s) and Scientific Research Publishing Inc. This work is licensed under the Creative Commons Attribution International License (CC BY 4.0).

http://creativecommons.org/licenses/by/4.0/ (c) (i) Open Access

\begin{abstract}
Background: Cirrhosis, an ineluctable development of chronic liver disease, still has high mortality throughout the world despite many advances in physiopathology and therapy. This high mortality is closely related to the unpredictable course of cirrhosis with numerous complications. Objective: To evaluate the predictive factors of death during cirrhosis. Materials and methods: This is an observational, descriptive study on cirrhotic patients hospitalized in the hepatology unit of the Center Hospitalier Universitaire in Bouake (Ivory Coast) during the period from January 01, 2018 to December 31, 2019. The study focused on the data collected in the medical files (paper format) of hospitalized cirrhotics and the death register of the service. The diagnosis of cirrhosis and the death of the cirrhotic were the main criteria for judgment. The secondary criteria defined were: history of cirrhosis, reasons for consultation, clinical signs, biological signs, complications of cirrhosis and the treatment received. The relationship between the parameters was expressed as an odds ratio (OR) with a $95 \%$ confidence interval (CI) and the significance threshold fixed at $\mathrm{p}<0.05$. Results: The study retained 206 files of cirrhotics including 146 men and 60 women. The hospital prevalence of cirrhosis was $44.17 \%$ and the mortality rate was $42.23 \%$. The deceased patients were mainly men with an average age of 49 years. The etiologies of cirrhosis were dominated by viral hepatitis $\mathrm{B}$, chronic alcohol poisoning and viral hepatitis $\mathrm{C}$, respectively $46.95 \%, 37.35 \%$ and $10.84 \%$. The predictors of death were: the presence of icterus $(\mathrm{OR}=1.89,95 \% \mathrm{CI}[1.08-3.30], \mathrm{p}=$ 0.036), hepatic encephalopathy ( $\mathrm{OR}=8.75,95 \% \mathrm{CI}[4.51-16.94], \mathrm{p}<0.001)$ and hepatocellular carcinoma $(\mathrm{OR}=2.23,95 \% \mathrm{CI}[1.25-3.98], \mathrm{p}=0.010)$; the presence in the biology of hepatic cytolysis ( $\mathrm{OR}=2.57,95 \% \mathrm{CI}[1.35-4.89], \mathrm{p}$ $=0.006)$, severe hepatocellular insufficiency $(\mathrm{OR}=2.57,95 \% \mathrm{CI}[1.38-4.77]$, $\mathrm{p}=0.004)$, severe renal insufficiency $(\mathrm{OR}=2.41,95 \% \mathrm{CI}[1.09-5.32], \mathrm{p}=$ $0.044)$ and hyperleukocytosis $(\mathrm{OR}=2.28,95 \% \mathrm{CI}[1.29-4.04], \mathrm{p}=0.007)$; Child-Pugh stage C $(\mathrm{OR}=19.64,95 \% \mathrm{CI}[9.02-42.74], \mathrm{p}<0.001)$; the pres-
\end{abstract}


ence on ultrasound of large liver and variable nodules $(\mathrm{OR}=4.16,95 \% \mathrm{CI}$ [2.02 - 8.58], $\mathrm{p}<0.001)$. Conclusion: Cirrhosis is a public health problem at the Bouake university hospiler center. Decompensated and complicated old cirrhosis, hepatic cytolysis, severe hepatocellular insufficiency, severe renal insufficiency and hyperleukocytosis, heterogeneous nodular large liver are the detrimental factors.

\section{Keywords}

Cirrhosis, Hepatocellular Carcinoma, Mortality, CHU Bouake

\section{Introduction}

Cirrhosis, an inevitable development of chronic liver disease, is a chronic and diffuse inflammatory disease of the liver, defined histologically by the association of fibrosis, hepatocyte necrosis and regeneration nodules [1]. In Europe, its etiology is dominated by the excessive and chronic consumption of alcohol. On the other hand, in Africa, precisely in sub-Saharan Africa, it is the viral hepatitis $\mathrm{B}$ and $\mathrm{C}$ which are the main cause [2] [3]. Mortality from cirrhosis is still high despite many advances in pathophysiology and therapy. This high mortality is closely related to the unpredictable course of enamel cirrhosis with numerous complications [4]. According to the $\mathrm{WHO}$, cirrhosis and hepatocellular carcinoma are responsible for 1.4 million deaths each year worldwide [5]. The occurrence of complications related to cirrhosis would increase the mortality of this disease in hospital. Several works carried out in Europe [2], America [6] and Africa [3] have studied different aspects of cirrhotic disease. However, in Côte d'Ivoire, to our knowledge, few studies exist on the prognostic factors of cirrhosis [7] [8]. The purpose of this study concerning cirrhotics who died in hospital was to investigate the predictors of mortality from cirrhosis in hospital.

\section{Material and Method}

This was a monocentric retrospective cohort study on cirrhotic patients hospitalized in the hepatogastroenterology unit of the Center Hospitalier Universitaire de Bouake (Ivory Coast) during the period from January 01, 2018 to December 31,2019 , over a period of 2 years. The study focused on the data collected in the medical files (paper format) of hospitalized cirrhotics and the death register of the service.

\subsection{The Study Protocol}

Two main judgment criteria have been identified:

- The diagnosis of cirrhosis posed by the combination of clinical, biological, ultrasound and endoscopic arguments, the anatomopathological examination not being carried out. 
- The death retained is that which occurred in hospitalization in the cirrhotic patient during the study period, in the hepatato-gastroenterology unit of the Center Hospitalier Universitaire de Bouake.

The following parameters were the secondary endpoints. These were: a history related to cirrhosis (viral hepatitis B, old C, old cirrhosis, number of previous hospitalizations, number of previous complications, puncture of ascites fluid). Clinical signs. The length of hospital stay in days. The reason for hospitalization. Biological signs (Blood count: Hyperleukocytosis defined by the number of white blood cells $>10.000$ elements $/ \mathrm{mm}^{3}$ or leukopenia $<5000$ elements $/ \mathrm{mm}^{3}$ ). Severe anemia defined by hemoglobin level $<8 \mathrm{~g} / \mathrm{dL}$. Thrombocytopenia defined by the number of platelets $<150.000$ elements $/ \mathrm{mm}^{3}$. Severe hyponatremia: $<125$ meq/L. Hyperkalemia $>5 \mathrm{meq} / \mathrm{L}$. The viral markers of hepatitis carried out: Ag HBs, Ac anti HBc, Ac anti HVC, Ac anti VHD. The following complications have been defined:

- Infection of ascites fluid (defined by exudative ascites with more than 250 elements $/ \mathrm{mm}^{3}$ ).

- Externalized digestive hemorrhage in the form of hematemesis and/or melena.

- Hepatocellular carcinoma diagnosed on the basis of tumor hepatomegaly and the presence of portal thrombosis, nodules of varying sizes on radiology (ultrasound or computed tomography).

- Hepatic encephalopathy classified according to the different stages.

- Hepatorenal syndrome associating functional renal failure (urea $>0.45 \mathrm{~g} / \mathrm{L}$ and creatinine $>14 \mathrm{mg} / \mathrm{L}$ ) and refractory ascites in a cirrhotic patient with edemato-ascitic decompensation.

- Cytolysis defined by an elevation of transaminases (ALT > $50 \mathrm{IU} / \mathrm{L}$ and/or ASAT > 50 IU/L).

- Cholestasis defined by an elevation in bilirubinemia (total bilirubin $>15$ $\mathrm{mg} / \mathrm{L}$ and/or conjugated bilirubin $>8 \mathrm{mg} / \mathrm{L}$ ).

- The treatment received was collected (antibiotics, diuretics, analgesics, lactulose, beta-blockers and paracentesis)

Sociodemographic characteristics and a history of comorbidity were the confounding factors.

\subsection{Statistics}

For input and analysis, we used SPSS ${ }^{\oplus}$ version 20 software and the figures were produced with Excel software. The analysis consisted initially of a descriptive analysis (means and frequencies) of the variables studied. In a second step, we established a predictive model of patient mortality based on the variables studied, using logistic regression. This relationship was expressed as an odds ratio (OR) with their $95 \%$ confidence interval (CI). The significance test fixed at $\mathrm{p}<0.05$.

\subsection{Ethical Consideration}

Under the investigation practices act, we protected the confidentiality of infor- 
mation that was collected during the investigation by assigning an anonymity number to each investigation sheet. In addition, an authorization was requested and obtained in advance from the administrative and medical authorities of the Bouake University Hospital Center.

\subsection{Results}

From January 2018 to December 2019, the gastroenterology unit registered 781 hospitalized patients, including 345 cases of cirrhosis, i.e. a hospital prevalence of cirrhosis of $44.17 \%$. Among the cirrhosis cases, 206 files were usable, including 87 deaths, representing a hospital mortality rate of $42.23 \%$. There was a predominance of men in their fifties with a sex ratio $(146 / 60)$ of 2.43 . The etiologies of cirrhosis were dominated by viral hepatitis $\mathrm{B}$, chronic alcohol poisoning and viral hepatitis C, respectively $46.95 \%, 37.35 \%$ and $10.84 \%$. Viral B and C coinfection was found in $1.94 \%$ of cases.

The general characteristics of cirrhotic patients are summarized in Table 1 and Table 2.

The death was not statistically related to age, gender, complications of ascites fluid infection and digestive hemorrhage, hyperkalemia and endoscopic signs of portal hypertension.

Death was significantly related to a history of complicated cirrhosis and paracentesis. Clinically, the presence of hepatomegaly, signs of decompensation, jaundice, edema and ascites were statistically related to death. Biologically, the laboratory results were disturbed in patients who died with cytolysis, leukocytosis, renal and hepatocellular failure. On abdominal ultrasound, hepatomegaly with nodules of varying sizes was significantly associated with death (Table 1).

In multivariate, the predictors of death are summarized in Table 3, Table 4 and Table 5.

Death was correlated with a history of paracentesis and known complicated cirrhosis. icterus, hepatomegaly, hepatic encephalopathy and hepatocellular carcinoma diagnosed during hospitalization were predictive of death. Regarding biology, death was correlated with hepatic cytolysis (ASAT > $50 \mathrm{IU} / \mathrm{L}$ and ALT > $50 \mathrm{IU} / \mathrm{L}$ ), hepatocellular insufficiency ( $\mathrm{TP}<60 \%$, Albuminemia $<30 \mathrm{~g} / \mathrm{L}$ ) with insufficiency renal (serum creatinine $>20 \mathrm{mg} / \mathrm{L}$ ) and hyperleukocytosis (number of white blood cells $>10,000$ elements $/ \mathrm{mm}^{3}$ ). On ultrasound, hepatomegaly with nodules of varying sizes was predictive of death.

Death was correlated with the progressive stage of the disease, and the prescription of lactulose or tramadol in hospital. However, the prescription of spironolactone, beta-blockers and paracentesis iterative in hospital was associated with a good course of cirrhotic disease (Table 5).

\section{Discussion}

The hospital prevalence and mortality rate of cirrhosis are still high as shown in this study, like the African literature [3] [4] [9] [10]. Cirrhotic patients were 
Table 1. Compared clinical and paraclinical characteristics of deceased and non-deceased cirrhotic patients.

\begin{tabular}{|c|c|c|c|}
\hline Variables & Deceased n (\%) & No deceased n (\%) & $\mathrm{p}$ \\
\hline \multicolumn{4}{|l|}{ Sex } \\
\hline - $\mathbf{M}$ & $62(71.26)$ & $84(79.59)$ & 1.000 \\
\hline$\bullet-\mathrm{F}$ & $25(8.74)$ & $35(29.41)$ & 1.000 \\
\hline Age $<50$ & $46(52.87)$ & $60(50.42)$ & 0.83 \\
\hline$>50$ & $41(47.13)$ & $59(49.58)$ & \\
\hline \multicolumn{4}{|l|}{ History } \\
\hline - Comorbidities & $17(19.54)$ & $12(10.08)$ & 0.085 \\
\hline - Known cirrhosis & $22(25.29)$ & $9(7.56)$ & 0.001 \\
\hline - Complications & $21(24.14)$ & $12(10.08)$ & 0.012 \\
\hline - Paracentesis & $13(14.94)$ & $5(4.20)$ & 0.014 \\
\hline \multicolumn{4}{|l|}{ Reasons for consultation } \\
\hline - Edemato-ascites decompensation & $18(20.70)$ & $42(35.29)$ & 0.034 \\
\hline - Icterus & $31(35.63)$ & $23(19.33)$ & 0.014 \\
\hline - Abdominal pains & $20(22.99)$ & $27(22.69)$ & 1.000 \\
\hline - Gastrointestinal bleeding & $10(11.49)$ & $12(10.08)$ & 0.92 \\
\hline - Hepatic encephalopathy & $3(3.45)$ & $2(1.69)$ & 0.72 \\
\hline \multicolumn{4}{|l|}{ Physical signs } \\
\hline - Ascite & $62(71.26)$ & $92(77.31)$ & 0.410 \\
\hline - Edema of the lower limbs & $43(49.43)$ & $74(62.18)$ & 0.092 \\
\hline - Icterus & $48(55.17)$ & $47(39.50)$ & 0.036 \\
\hline - Lateral venous circulation & $22(25.29)$ & $24(20.17)$ & 0.483 \\
\hline - Large liver & $64(73.56)$ & $55(46.22)$ & 0.001 \\
\hline - Large spleen & $11(12.64)$ & $12(10.08)$ & 0.725 \\
\hline - Lenght of hospital stay $\leq 7$ & $63(72.41)$ & $84(70.58)$ & 0.896 \\
\hline - Lenght of hospital stay $>7$ & $24(27.59)$ & $35(29.41)$ & \\
\hline \multicolumn{4}{|l|}{ Biology } \\
\hline - Creatinemia $(\mathrm{mg} / \mathrm{L})>20$ & $18(21.43)$ & $12(10.17)$ & 0.044 \\
\hline - Blood urea $(\mathrm{g} / \mathrm{L})>$ ou $=0.45$ & $28(33.33)$ & $26(22.03)$ & 0.104 \\
\hline - Kaliemia $(\mathrm{meq} / \mathrm{L})>$ ou $=5$ & $14(20.00)$ & $22(18.97)$ & 1.000 \\
\hline - Natremia $(\mathrm{meq} / \mathrm{L})<125$ & $5(7.14)$ & $3(2.59)$ & 0.267 \\
\hline - Total bilirubin $(\mathrm{mg} / \mathrm{L})>10$ & $52(92.86)$ & $107(94.69)$ & 0.897 \\
\hline - Prothrombin nevel (\%) $<60$ & $63(75.90)$ & $65(55.08)$ & 0.004 \\
\hline - Albuminemia $(\mathrm{g} / \mathrm{L})<30$ & $54(78.26)$ & $72(62.61)$ & 0.040 \\
\hline - $\operatorname{ALT}(\mathrm{UI} / \mathrm{L})>50$ & $59(76.62)$ & $65(56.03)$ & 0.006 \\
\hline - $\operatorname{ASAT}(\mathrm{UI} / \mathrm{L})>50$ & $69(89.61)$ & $86(73.50)$ & 0.011 \\
\hline - White blood cells (elements $/ \mathrm{mm}^{3}$ ) $>10,000$ & $45(51.72)$ & $38(31.93)$ & 0.007 \\
\hline - Hemoglobin $(\mathrm{g} / \mathrm{dl})<8$ & $21(24.14)$ & $30(25.21)$ & 0.990 \\
\hline \multicolumn{4}{|l|}{ Ultrasound } \\
\hline - Ascit & $55(87.30)$ & $88(85.44)$ & 0.915 \\
\hline - Nodule variable sizes & $34(53.97)$ & $38(36.89)$ & 0.046 \\
\hline - Homogeneous nodules & $29(46.03)$ & $60(58.25)$ & 0.170 \\
\hline - Portal thrombosis & $4(6.65)$ & $9(8.74)$ & 0.768 \\
\hline - Large liver & $50(79.37)$ & $49(47.57)$ & 0.001 \\
\hline - Large spleen & $12(19.05)$ & $24(23.30)$ & 0.652 \\
\hline \multicolumn{4}{|l|}{ Endoscopy } \\
\hline - Esophageal varices & $16(84.21)$ & $48(84.48)$ & 1.000 \\
\hline - Red signs & $8(42.10)$ & $12(20.69)$ & 0.122 \\
\hline
\end{tabular}


Table 2. Comparative prognostic and therapeutic characteristics of deceased and non-deceased cirrhotic patients.

\begin{tabular}{|c|c|c|c|}
\hline Variables & Deceased n (\%) & No deceased n (\%) & $\mathrm{p}$ \\
\hline \multicolumn{4}{|l|}{ Complications } \\
\hline - Liquid ascite infection & $5(5.75)$ & $7(5.88)$ & 1.000 \\
\hline - $\mathrm{HCC}$ & $41(47.13)$ & $34(28.57)$ & 0.010 \\
\hline - Gastrointestinal bleeding & $20(22.99)$ & $22(18.49)$ & 0.537 \\
\hline - Hepatic encephalopathy & $53(60.92)$ & $18(15.13)$ & $<0.001$ \\
\hline - Hepatorenal syndrome & $4(4.60)$ & $0(0.00)$ & 0.031 \\
\hline \multicolumn{4}{|l|}{ Pronostic score } \\
\hline - Child-Pugh A & $0(0.00)$ & $9(7.83)$ & 0.027 \\
\hline - Child-Pugh B & $26(32.50)$ & $95(82.61)$ & 0.001 \\
\hline - Child-Pugh C & $54(67.50)$ & $11(9.57)$ & $<0.001$ \\
\hline \multicolumn{4}{|l|}{ Treatment } \\
\hline - Fluoroquinolone & $12(13.79)$ & $25(21.01)$ & 0.25 \\
\hline - Tramadol & $69(79.31)$ & $68(57.14)$ & 0.001 \\
\hline - Furosemide & $8(9.20)$ & $12(10.08)$ & 1.000 \\
\hline - Spironolactone & $5(5.75)$ & $31(26.05)$ & $<0.001$ \\
\hline - Lactulose & $72(82.76)$ & $73(61.34)$ & 0.002 \\
\hline - Betablockers & $9(10.34)$ & $31(26.05)$ & 0.008 \\
\hline - Blood transfusion & $19(21.84)$ & $30(25.21)$ & 0.69 \\
\hline - Number paracentesis $\geq 2$ & $22(25.29)$ & $54(45.38)$ & 0.005 \\
\hline
\end{tabular}

Table 3. Clinical factors predictive of death.

\begin{tabular}{lccc}
\hline \multicolumn{1}{c}{ Factors } & Odds ratio & IC à 95\% & $\mathrm{p}$ \\
\hline History of cirrhosis & & & \\
- Paracentesis: yes vs No & 4.01 & {$[1.37-11.70]$} & 0.014 \\
- Complications: yes vs No & 2.83 & {$[1.31-6.14]$} & 0.012 \\
- Known cirrhosis: yes vs No & 4.13 & {$[1.80-9.52]$} & 0.001 \\
Clinical signs & & & \\
- Icterus: yes vs No & 1.89 & {$[1.08-3.30]$} & 0.036 \\
- Large liver: yes vs No & 3.24 & {$[1.78-5.88]$} & $<0.001$ \\
Complications diagnosed in hospital & & & \\
- HCC: yes vs No & 2.23 & {$[1.25-3.98]$} & 0.010 \\
- Hepatic encephalopathy: yes vs No & 8.75 & {$[4.51-16.94]$} & 0.001 \\
\hline
\end{tabular}


Table 4. Paraclinical factors predictive of death.

\begin{tabular}{lccc}
\hline \multicolumn{1}{c}{ Factors } & Odds ratio & IC à 95\% & p \\
\hline Biological signs & 2.57 & {$[1.35-4.89]$} & 0.006 \\
- ALT (UI/L): $>50 v s \leq 50$ & 3.11 & {$[1.34-7.20]$} & 0.011 \\
- ASAT (UL/L): $>50 v s \leq 50$ & 2.41 & {$[1.09-5.32]$} & 0.044 \\
- Creatinemia (mg/L): $>20 v s \leq 20$ & 2.57 & {$[1.38-4.77]$} & 0.004 \\
- Prothrombin nevel $(\%):<60 v s \geq 60$ & 2.15 & {$[1.08-4.27]$} & 0.040 \\
- Albuminemia $(\mathrm{g} / \mathrm{L}):<30 v s \geq 30$ & 2.28 & {$[1.29-4.04]$} & 0.007 \\
- White blood cells $\left(\mathrm{elements} / \mathrm{mm}^{3}\right):>10,000 v s \leq 10,000$ & & & \\
Ultrasound signs & 4.16 & {$[2.02-8.58]$} & $<0.001$ \\
- Large liver: yes $v s$ No & 2.01 & {$[1.06-3.79]$} & 0.046 \\
\hline
\end{tabular}

Table 5. Prognostic and therapeutic factors predictive of death.

\begin{tabular}{lccc}
\hline \multicolumn{1}{c}{ Factors } & Odds ratio & IC à $95 \%$ & $\mathrm{p}$ \\
\hline $\begin{array}{l}\text { Pronostics factors } \\
\text { - Child-Pugh C: yes vs No }\end{array}$ & 19.64 & {$[9.02-42.74]$} & 0.001 \\
Treatment & & & \\
- Tramadol: yes vs No & 2.88 & {$[1.53-5.42]$} & 0.001 \\
- Spironolactone: yes $v s$ No & 0.17 & {$[0.06-0.47]$} & 0.000 \\
- Lactulose: yes vs No & 3.02 & {$[1.55-5.90]$} & 0.002 \\
- Betablockers: yes $v s$ No & 0.33 & {$[0.15-0.73]$} & 0.008 \\
- Number of paracentesis: $\geq 2 v s<2$ & 0.41 & {$[0.22-0.74]$} & 0.005 \\
\hline
\end{tabular}

generally men in their fifties as reported in several studies in Africa and Europe [2] [10] [11]. Patients very often consult at the edemato-ascitic decompensation stage as reported by our results and other African studies [12]. This observation testifies to the delay in consulting cirrhotic patients, most often at the decompensation stage where the presence of ascites reflects the development of cirrhosis [9] [10] [13]. In this study the etiology of cirrhosis was dominated by viral hepatitis B and alcohol. Chronic alcoholism takes an important place in the etiology of chronic liver disease in Africa due to the excessive consumption of alcohol most often adulterated by our young and often idle populations as reported by other African authors [8] [10] [14]. Ultrasound anomalies are dominated by nodular hepatomegaly with nodules of varying sizes [3] [9]. Indeed, abdominal ultrasound allows, in addition to the non-invasive diagnosis of cirrhosis [15], to strongly suspect hepatocellular carcinoma in $26 \%$ of cases when the liver is heterogeneous with nodules of variable sizes [9]. Digestive fibroscopy (FOGD) was poorly performed (37.38\%) due to its high cost and the clinical in- 
stability of hospitalized cirrhotic patients. The endoscopic anomalies were dominated respectively by grade 2 and 3 esophageal varices (78\%) with the presence of red signs in $26 \%$ of the cases and a mosaic gastropathy (49.35\%). These results are consistent with African literature [9] [16]. The complications of hepatocellular carcinoma and hepatic encephalopathy diagnosed in the hospital were the same as those described by African and European authors [1] [17] [18] [19]. In multivariate analysis, concerning sex, the results differ according to the authors. Some authors do not find a link between the male sex and death in the cirrhotic patient [10] [18] [19] as in our work. On the other hand, other authors have found an association between death and the male sex [7] [12] [17].

The death in men could be explained by the increased risk of developing HCC, higher alcohol consumption and a high prevalence of HBV. These factors could worsen the prognosis of cirrhosis regardless of the etiology [20]. The age of onset of death less than 50 years has been found in several studies in Africa [10] [18], unlike in Europe [19] [20] where death occurs after 50 years. In this study, the history of complicated and decompensated cirrhosis was predictive of death. Hepatic encephalopathy testifying to severe hepatic insufficiency is strongly implicated in mortality during cirrhotic disease [17] [18]. Jaundice has been reported by several authors to be a predictor of death [10] [18] [21]. Hepatomegaly could be related to cirrhosis itself or to the most dreaded complication of cirrhosis: hepatocellular carcinoma (HCC). The occurrence of HCC on cirrhosis reduces the short-term survival of the cirrhotic patient [1] [17]. The occurrence of ascites in cirrhotics is known to be a factor of poor prognosis, especially infected ascites [10] [14] [18]. Some authors have shown that infection with ascites fluid significantly reduces survival in cirrhotics [8] [17]. The digestive hemorrhage was found mainly in the event of death $(\mathrm{p}=1.000)$ not significantly. According to several studies, digestive hemorrhage is frequently cited as a detrimental factor in cirrhosis [10] [18]. The prognostic score studied was that of the Child-Pugh classification. The prognostic value of Child Pugh's score in cirrhosis has been the subject of several publications [7] [19] [22]. The evolution of cirrhosis was significantly linked to the Child-Pugh prognosis stage with a very pejorative stage $\mathrm{C}(\mathrm{p}<0.001 ; \mathrm{OR}=19.64 ; \mathrm{CI}=9.02-42.74)$ according to the data in the literature [7] [14] [17]. Regarding biology, the results were generally disturbed in the cirrhotic patients who died in our study. We found an independent association between severe renal impairment (creatinine $>20 \mathrm{mg} / \mathrm{L}$ ), hepatic cytolysis, hepatic impairment and death. Biological balance abnormalities have been frequently found in several studies concerning the development of cirrhosis. According to Attia in a study carried out in Ivory Coast, the patients having a serum creatinine $>15 \mathrm{mg} / \mathrm{L}$ on admission died more than those whose creatinine is $\leq 15 \mathrm{mg} / \mathrm{L}$ with a risk of death multiplied by 4.5 of cirrhotic in case renal failure [7] [13]. Other authors in France and Morocco [18] [19] have also implicated renal failure in the mortality of the cirrhotic patient. Claire et al. have shown that an ASAT value $\geq 80 \mathrm{IU} / \mathrm{L}$ was a factor in poor prognosis [1]. Hepa- 
tocellular insufficiency (HCI) with severe hypoalbuminemia and hypoprothrombinemia was associated with death in several studies [7] [14] [18]. Indeed, the impact of the HCI on the survival of the cirrhotic has long been proven so much that it is an important element of the classification of Child-Pugh [7]. Dyskalemia has been reported in several studies as a predictor of death [8] [13] [18]. Observation which was not made in this study. Hyperleukocytosis is a reflection of sepsis frequently found in cirrhotic patients [17], due to a global dysfunction of innate and adaptive immunity inducing a greater susceptibility to bacterial infections [23]. The presence of signs of portal hypertension on upper gastrointestinal endoscopy is associated with high mortality [14] [17]. For some authors, it is rather the rupture of esophageal varices which is implicated in mortality in cirrhotic patients [10]. In our study, no endoscopic signs were significantly linked to death. This observation could be explained on the one hand, by the very low percentage (37.38\%) of esogastroduodenal fiborscopy (OGDF) carried out in order to look for signs of portal hypertension and on the other hand, by the systematic prescription of beta-blockers as part of the primary prevention of digestive haemorrhage in cirrhotics in the event of VO. In fact, the prevention of rupture of esophageal varices by beta-blockers improves survival in cirrhotics [8].

The limit of this study is mainly related to the relatively high cost of certain examinations and the insufficient technical platform which did not allow a more exhaustive exploration of certain data. Nevertheless, this study made it possible to highlight in a significant way the predictive factors of mortality in cirrhotic patients in an Ivorian hospital service.

\section{Conclusion}

Cirrhosis is a public health problem at the Bouaké University Hospital Center (Ivory Coast) with hospital prevalence and mortality still high. The diagnosis is made at the stage of complications and they are dominated by hepatocellular carcinoma and hepatic encephalopathy. In single or multivariate analysis, the history of complicated cirrhosis, the presence of signs and treatment related to hepatocellular carcinoma, hepatic encephalopathy, biochemical activity, severe hepatocellular and renal failure were correlated with death. An early diagnosis of cirrhosis and its complications, as well as regular monitoring, will help detect and correct these factors. This also involves screening upstream for viral hepatitis and raising awareness about excessive alcohol consumption.

\section{Conflicts of Interest}

The authors declare no conflicts of interest regarding the publication of this paper.

\section{References}

[1] Claire, I.R. and Jean-Pierre, V. (1989) Prognostic Factors of Death in Cirrhosis of 
the Liver. Medicine/ Science, 5, 320-330.

[2] Condat, B., Remy, A.J., Jouannaud, V., Lahmek, P., Rosa, I., Cadranel, J.F. et al. (2015) The Use of Cirrhosis Care in the Hepato-Gastroenterology Departments of French General Hospitals, 2012. Bulletin Épidémiologique Hebdomadaire, 24-25, 450-456.

[3] Mbendi, N.C., Aliocha, N., Zingondo, B.J.C., Manangama, C.N., Taty, P.L., Ngoma, J.A., et al. (2018) Epidemio-Clinical and Evolutionary Aspects of Cirrhosis of the Liver in Kinshasa: Multicentric Study. Annals of African Medicine, 11, 2814-2282.

[4] Noah, N.D., Bagnaka, S.A.F.E., Andoulo, F.A., Bilounga, J.N. and Namme, H.L. (2016) Complications and Prognosis of Cirrhotic Patients at the Douala General Hospital in Cameroon. Journal of Applied Medical Sciences, 5, 43-52.

[5] WHO (2015) Prevention and Control of Viral Hepatitis.

[6] Belcher, J.M., Guadalupe, G.-T., Arun, J.S., Bhogal, H., Lim, J.K., Ansari, N., et al. (2013) Association of AKI with Mortality and Complications in Hospitalized Patients with Cirrhosis. Hepatology, 57, 753-762. https://doi.org/10.1002/hep.25735

[7] Attia, K.A., Ackoundou-N'guessan, K.C., N'dri-yoman, A.T., Mahassadi, A.K., Messou, E., Bathaix, Y.F., et al. (2008) ChildPugh-Turcott versus Meld Score for Predicting Survival in a Retrospective Cohort of Black African Cirrhotic Patients. World Journal of Gastroenterology, 14, 286-291. https://doi.org/10.3748/wig.14.286

[8] Yao Bathaix, M.F., Baguy, A., Mahassadi, K.A., Okon, J.-B., Kissi-Anzouan, Y.H., Doffou, S., et al. (2015) Prognostic Factors for Cirrhosis Hospital in Abidjan (Ivory Coast). Open Journal of Gastroenterology, 5, 103-109. https://doi.org/10.4236/ojgas.2015.57017

[9] Sawadogo, W.A. (2012) Study of the Epidemiological, Clinical, Paraclinical, Etiological and Progressive Aspects of Cirrhosis of the Liver in the Medical Department of Chu De Bobo-Dioulasso: About 87 Cases. Thesis, University of Ouagadougou, Burkina Faso.

[10] Sehonou, J., Kodjoh, N., Sake, K. and Mouala, C. (2010) Liver Cirrhosis in Cotonou, Republic of Benin: Clinical Aspects and Factors Related to Death. Médecine Tropicale, 70, 375-378.

[11] Fattovich, G., Giustina, G., Degos, F., Tremolada, F., Diodati, G., Almasio, P., et al. (1997) Morbidity and Mortality in Compensated Cirrhosis Type C: A Retrospective Follow-Up Study of 384 Patients. Gastroenterology, 112, 463-472. https://doi.org/10.1053/gast.1997.v112.pm9024300

[12] Perri, G.A. (2013) Ascites in Patients with Cirrhosis. Canadian family physician, 59, 538-540.

[13] Attia, K., N'dri-yoman, A.T., Mahassadi, A.K., Ackoundou-N'guessan, K.C. and Doffou, A.S. (2007) Impact of Renal Failure on the Survival of a Cohort of 132 Black African Cirrhotics. Revue International des Sciences Médicales, 9, 29-34.

[14] Dicko, M.Y. (2008) Evolutionary Aspects of Cirrhotic Disease: One Year of Follow-Up at the Gabriel Touré Teaching Hospital. Thesis, University of Bamako, Bamako.

[15] Diarra, M., Konaté, M., Diarra, A., Kane, M., Touré, M., Dembélé, M., et al. (2009) Interest of Ultrasound in the Diagnosis of Cirrhosis in Tropical Environments. Journal Africain d Hépato-Gastroentérologie, 3, 125-129.

https://doi.org/10.1007/s12157-009-0095-8

[16] Cherrad, M., Rethel, R. and Sarah, Y. (2018) Cirrhosis and Complications. Thesis, Univ Abou Bekr Belkaid, Tlemcen, Algeria. 
[17] Asma, O.-K., Najet, B., Nabil, A., Msadek, A., Nabyl, B.M., Mohamed, H.D., et al. (2010) Survival in the African Black Cirrhotic. Tunisia Medical, 88, 804-808.

[18] Charif, I., Saada, K., Mellouki, I., El Yousfi, M., Benajah, D., El Abkari, M., et al. (2014) Predictors of Intra-Hospital Mortality in Patients with Cirrhosis. Open Journal of Gastroenterology, 4, 141-148. https://doi.org/10.4236/ojgas.2014.43021

[19] Robert, R. and Veinstein, A. (2003) Prognosis of the Patient with Cirrhosis in Intensive Care. Gastroentérologie Clinique et Biologique, 27, 877-881.

[20] Péquignot, F., Hillon. P., Antona, D., Ganne, N., Zarski, J.-P., Méchain, M., et al. (2008) National Estimate of Associated Mortality Attributable to Hepatitis C and Hepatitis B in Mainland France in 2001. Bulletin Épidémiologique Hebdomadaire, 27, 237-240.

[21] Razafimahefa, S.H., Rabenjanahary, T.H., Rakotoarivelo, R.A., Ramilitiana, B., Ramanampamonjy, R.M. and Rajaona, H.R. (2010) Causes of Mortality in a Population of Madagascan Cirrhotic Patients. Médecine Tropicale, 70, 163-165.

[22] Gex, L., Bernard, C. and Spahr, L. (2010) Scores in Hepatology: Child-Pugh, MELD and Maddrey. Revue Médicale Suisse, 6, 1803-1808.

[23] Allaire, M., Cadranel, J.F., Ollivier-Hourmand, I., Garioud, A. and Dao, T. (2017) Cirrhosis and Bacterial Infections Excluding Infection of Ascites Fluid. First Part: Physiopathological Mechanisms and Clinical Features. Hepato-Gastro \& Digestive Oncology, 24, 241-248. 